Catherine T. Kwantes ${ }^{1 *}$, Siddardh Thirumangai Alwar ${ }^{1}$, Stephanie J. Cragg ${ }^{1}$, Magali Feola ${ }^{2}$ ${ }^{1}$ University of Windsor, Windsor, ON, Canada ${ }^{2}$ Objectif France Inde, Bangalore, India

\title{
Enhancing Foster Care Home NGO Sustainability via Social Franchising
}

DOI: 10.7595/management.fon.2020.0014

Abstract:

Research Question: This paper investigates how the social franchising approach may enhance the sustainability and capability of Foster Home NGOs in the Global South. Motivation: While many programmes exist to address issues such as poverty and lack of education for children in nations of the Global South, many operate in isolation, and are grassroots and/or stand-alone operations. Little research has been undertaken to understand how various approaches to organizational sustainability may be enacted for non-governmental organizations (NGOs) seeking to provide care for children in foster care homes. Our goal was to apply franchising and social franchising concepts as a framework for NGOs and non-profit organizations to use as a way of enhancing both the capability of achieving their mission as well as a method of organizational sustainability. Idea: Much of the literature on social franchising has been in the area of providing health care and services - however, this model may be useful to enhance the sustainability for NGOs and non-profit organizations that provide other critical services as well, such as foster care homes in the Global South. Findings: The social franchising model offers a concrete and actionable business model to foster home organizations with multiple homes to standardize care delivery as well as develop a strong core organization. Contribution: This paper explores how applying the social franchising model could enhance sustainability of NGOs with foster care home programmes, as well as some of the opportunities and challenges in applying this model to such NGOs and non-profit organizations.

Keywords: social franchising, non-profit, NGO, organization, Global South

JEL clasiffication: L31, D2, A13, L44

\section{Introduction}

The "urbanization of poverty" (see Mitlin, 2016) has resulted in an increased recognition of the needs of impoverished families in the Global South. While many programmes exist to address issues such as poverty and lack of education for children in nations of the Global South, many operate in isolation, and are grassroots and/or stand-alone operations. Amies (2000) notes "Although individual efforts can and do create units that work well, there is rarely any expansion strategy or methodology for replication of the successful pilot, no mechanism for passing on "best practices." There is usually little coordination, little monitoring, minimal feedback, very little learning from mistakes, and not much sharing of experience. There is also a lack of market research before starting a project, often no real plan or marketing, rarely an operating procedure that has been tested, no cash flow forecast or measurement" (p.38).

A recent approach that addresses these concerns is social franchising. The idea of social franchising is relatively new, and the concept has been interpreted and enacted in a variety of ways (Brown, 2014). As a new area of both practice and research, how to prepare for social franchising, accomplish it, and evaluate its success has some distinct challenges. It can take on multiple forms that can be difficult to define as "the nature of non-profit organizations and social enterprise is diverse, making it difficult to generate and test theory in the field with consistency" (Crawford-Spencer \& Cantatore, 2016, p. 29).

Social enterprises are difficult to establish and are particularly liable to fail (Hayllar \& Wettenhall, 2011), and social franchises are no exception to this, yet this approach also offers some unique opportunities, especially 
the opportunity to increase the capability and sustainability of the organization. Given that NGOs typically operate with limited resources yet vast needs, social franchising provides a strategy for generating capital, enhancing sustainability, improving quality and expanding impact (Cumberland \& Litalien, 2018). Most social franchising efforts have been in the area of providing health care and services - however, this model offers opportunities for organizations providing services such as foster care in the Global South.

Children who live in urban poverty are among the most vulnerable to the negative effects of poverty, with the impact of poverty both "devastating and lifelong" (Stewart \& Okubo, 2017, p. 5). Foster care homes are therefore an opportunity to protect children from these risks, and to give children opportunities for the future that they would not have had otherwise (Eiðsdóttir, 2016). Given the importance of the mission of foster care homes, and given the scope of the need for care of children who live in poverty in the Global South, the social franchise concept may increase the scope and impact of NGOs working to address the needs of children.

\section{Literature Review}

2.1 Social Franchises. Social franchises are geared towards alleviating a social problem (Alur, 2013) and do this by leveraging commercial franchising approaches to increase the scale of organizational impact (Beckmann \& Zeyen, 2014), including market research, marketing, cash flow forecast and measurement, and employee training. Kaufmann and Eroglu (1999) note that in the US "Howard Johnson's became the ubiquitous "host of the highway" by providing wary travellers the assurance of a predictably consistent dining experience" (p. 72). Similar to such business franchises that emphasize standardization of products and services both internally and for clients (Kellner, 2017), social franchises focus on consistency of service delivery.

Social franchising is increasingly recognized as a viable approach for social enterprises to achieve impact and to increase organizational sustainability, as it has been suggested that the "expansion of franchising into the social realm has implications for global development and may impact the lives of millions of individuals" (Cumberland \& Litalien, 2018, p. 139). Alur and Schoormans (2011), for example, conducted an exploratory field study in India focusing on healthcare organizations, concluding that the key to successful franchising is training and support to maintain the quality of the services that they offer. Developing standards to assure consistency, then training to uphold those standards is paramount for social franchises. For foster care homes, this means that activities related to care for children with respect to psychosocial development, education, safety, and nutrition, as well as the standards of that care, are standardized and consistent regardless of who is providing financial support for the home or who the caretaker is in the home.

2.2 Social Franchise Strategies. NGOs around the world emerge to deal with various social needs through products and services that aim at addressing social issues. Most of these organizations find it difficult to reach many people or have the intended impact due to limited resources and geographic reach of the communities with similar social needs (Asemota \& Chahine, 2017). It is evident that starting a new project or organization from scratch requires a lot of time and resources and establishing a social enterprise to achieve the level of social impact can take years and might involve a number of years before achieving success which can be expensive (Pereira et al., 2015). Instead of building an organization from scratch, some organizations can utilize different scaling models, which allows for initial NGO's success to generate additional impact. And this scaling can also help in identifying problems and adaptations that can help improve the overall organizational functioning. Studies show that when projects and organizations have proven to be successful in solving a particular social issue, they should be encouraged to replicate it in other parts of the world with similar social problems (Berelowitz, Richardson \& Towner, 2013).

One of the most important things to consider during replication is whether the organization is scaling out or scaling up (Bloom \& Chatterji, 2009). Scaling out refers to the opportunity to expand the social impact by introducing the solution to new territories with the right strategy and effective adaptation to the new local context. Scaling out can be considered as scaling horizontally as it aims at impacting wider numbers of people and regions. Scaling up, on the other hand, refers to the replication of an innovative solution to a social problem that involves affecting the broader system that influences the root cause of the problem (Lyon \& Fernandez, 2012). Scaling up can be considered as scaling vertically as it aims at impacting the larger system through policy change. Although the traditional franchising model focuses on scaling out, it is important for the NGO/organization to decide the extent to which it decides to address the social need (Conway, 2015).

Organizations that consider franchising as a replication strategy should examine different elements that need to be replicated among the franchisees. Among these elements, some factors might be the core competency of the organization which cannot be modified while other elements can have contextual flexibility (Hurley, 2016). Some of the key replicable elements for successful replication of the franchising model are 
vision, idea, knowledge, training, health \& safety, process, brand, monitoring \& evaluation and IT systems (Berelowitz, Richardson \& Towner, 2013).

2.3 Social Franchise Development. Keeping standards consistent and high while a social franchise is growing can be challenging. While the main goal of social franchising is to expand the social benefits of the organization, rather than financial gain (Asemota \& Chahine, 2017), there are a variety of ways in which social franchises can expand their services. Weber, Kroger, and Demirtas (2015) conducted an analysis of 358 national and international European social enterprises which revealed four main scaling strategies. The first scaling strategy is capacity building, which is expanding through offering the same services as the original franchise location, and advertising to the same client base. A second scaling strategy is strategic expansion, which is when the social franchise offers new products or services or advertises to a new market base. The third scaling strategy is called contractual partnerships, which is when new social franchise locations are established through set contractual partners. The final scaling strategy is known as knowledge dissemination and occurs when the social franchise's social impact model is disseminated, but no social franchise expansion is desired.

Asemota and Chahine (2017) developed a theoretical framework for use in understanding the development of social franchising. This framework suggests that there are seven developmental stages of the social franchising process: (1) pre-replication, when the organization is considering social franchising; (2) replication readiness, when the organization assesses their ability to engage in social franchising; (3) replication capital, when the organization evaluates the various forms of capital needed and available to engage in social franchising; (4) franchise manual development, when the organization develops their operating manual; (5) franchisee selection, selecting applicable individuals or organizations which may be interested in franchising; (6) training, communication and support; and (7) evaluation.

The first stage of the developmental process, according to the authors, is pre-replication, when the organization is considering social franchising. Pre-replication refers to the phase in which the organization assesses a potential franchisee's alignment with the NGO's vision and mission statements, financial resources, local knowledge and managerial expertise to successfully implement the scaling model and may run a cost-benefit analysis to identify if social franchising is beneficial. In this stage, therefore, it is extremely important to ensure that potential franchisors are sufficiently developed to be able to support franchisees, that franchisees understand the local conditions, and that the service being offered is a good fit within the local environment (Asemota \& Chahine, 2017). For foster home agencies, this may be in determining what the core population is that the organization wishes to serve. For example, organizations may see the greatest need is to provide care for orphans, or for certain age groups, or for those who live in specific areas that have challenges such as slums.

The second stage is replication readiness, when the organization assesses their ability to engage in social franchising. Tracey and Jarvis (2007), in their case study on a social franchise in the UK noted that its failure was in large part due to becoming a social franchise too early, without becoming a stable franchisor first, then undertaking the necessary reviews to ensure that franchisees were compatible with their vision and ensuring that they were able to provide the necessary support to a new franchisee. In the social franchising model of service provision, NGOs require a significant amount of investment in terms of financial and human resources (Montagu, 2002), and there is a high level of economic risk for social franchises (Zafeiropoulou \& Koufopoulos, 2013) when significant outcomes are also dependent on donations and work is being conducted by volunteers. Thus, a careful alignment of franchisor vision and the capability of a potential franchisor is critical to consider. For foster care home programmes, this would suggest the benefit in creating a team to conduct interviews and assessments and provide recommendations for social franchising (The Annie E. Casey Foundation, 2013). The team can modify The Kinship Treatment Foster Care Initiative Toolkit (Foster Family-based Treatment Association, 2015) to assist in their assessment.

The third stage mentioned by the authors is replication capital, when the organization evaluates the various forms of capital needed and available to engage in social franchising. In this stage it is important to consider the legal and ethical concerns associated with obtaining capital, as well as how funds flow between the franchisor and franchisees (Asemota \& Chahine, 2017). For foster care homes, this involves a strategic plan for developing relationships with potential funders for the project - relationships with funders is critical for sustainable capital. Understanding what funders expect with regard to reports on spending and impact and meeting reporting expectations is important for continued support by granting entities. Thus, a strategic plan for communicating with current and potential funders of a foster care home social franchise is a crucial part of determining what capital is available for social franchising activities. At this stage, care to determine expenses and capital requirements is crucial, including making connections with donors who are willing to support the mission of the organization and provide needed funding for the organization on an ongoing basis. 
The fourth stage is franchise manual development, when the organization develops their operating manual. Standard operating procedures that the franchisees are expected to follow must be carefully developed and operationalized - they should be consistent with the vision and mission of the social franchisor yet allow for flexibility as needed in various specific contexts. This standardization is critical to the sustainability, success, and impact of the social franchise. This standardization, in the case of social franchising, is critical to establishing standards of care and operations in order to ensure that the services provided are consistent and of high quality. For foster care homes, there are governmental, or legal, regulations as well as clear guidelines for the care of children (for example, Cantwell, Davidson, Elsley, Milligan \& Quinn, 2013). At this stage of social franchising, the organization should be operationalizing those guidelines with concrete steps for how the guidelines should be put into practice in a way that makes sense in the given context, one the NGO operates in. Further, before opening foster home franchises clear policies related to how the foster homes will be evaluated should be developed, as well as the criteria that they will be evaluated on and how often evaluations will occur (Asemoda \& Chahine, 2017). The head office should work to ensure that evaluations and criteria are standardized across all foster home franchises. Foster homes should be evaluated on the safety of the children, the safety of the home, medical and educational support provided by the homes, as well as the social and psychological supports provided by the homes

The fifth stage is franchisee selection, selecting applicable individuals or organizations which may be interested in franchising (Asemota \& Chahine, 2017). Potential franchisees may be interested in entering a social franchise arrangements for a number of different reasons, and the incentivisations may impact the success of the relationship (Cumberland and Litalien, 2018). For example, there are many faith-based organizations as well as secular organizations that serve those in need, and who seek to provide positive outcomes for those whom they serve. However, while the missions of these types of organizations may be similar, the approaches may differ. Frame (2017), for example, noted that in the organizations he reviewed, discussions of religion and faith were strongly present in the faith-based organizations, and impacted the types of outcomes that the organizations hoped to achieve. Secular NGOs did not ignore religious faith and saw value in it, but as it was not a key component of their approach, the outcomes they worked towards differed from the faith based organizations as they did not include behavioural outcomes that could be perceived as consistent with religious expectations. Thus, care to discuss the philosophical underpinnings of social efforts between a franchisor and a franchisee are critical as disagreement in this area, or a misalignment of outcome expectations can cripple a social franchising effort. The selection of franchisees is critical (Sivakumar \& Schoorman, 2011) as the franchisor and the franchisee enter into an interdependent relationship with the same vision and goal. The more closely aligned the franchisor and the franchisee are, and the stronger the relationship between the two, the more successful franchises tend to be (Brown \& Dev, 1997). Foster homes located in communities are likely to have varied relationships with those in the community, depending on specific locations (Eiðsdóttir, 2016) and the social franchise model allows for some regional variations. Given these variations, and the need for them, it is even more incumbent upon the franchisor to exert great care in selecting franchisee foster homes where the vision of how children are cared for is a shared one.

The sixth stage is training, communication and support. It is important to engage in continuous training for franchisees in order to ensure that franchisees are able to function with the most up-to-date knowledge (Asemota \& Chahine, 2017). Frequent training reinforces the importance of complying with standard operating procedures. NGO employees tend to operate in environments that are stressful, and turnover levels may be high (Khurshid, Butt, \& Muzaffar, 2012). Thus, clear training, both formal and informal, is critical to ensure that the standards set by the franchisor are understood and maintained. However, communication to ensure that the franchisor is aware of the contexts within which the franchisees work is also important to ensure that the standards are practical, relevant, and lead to the desired impact. Interaction with the community the NGO seeks to serve, and feedback from them on how various practices impact their wellbeing is also important at this stage to ensure the relevance of the social franchise activities. For foster care home agencies, communication must flow both ways as when children are being cared for it is critical that the franchisees have what is required to care for the children, but also adhere to the standards set by the franchise (Cantwell et al, 2013).

The final stage is evaluation which should ensure equal contributions from the franchisor and franchisees and to appraise the social impact of the franchise. Further, evaluation is important due to the costs inherent in the social franchise model (Montagu, 2002) and the responsibility to report to funders what the impact of their gifts were, as well as to develop a strong performance record to attract further funding. NGO funding is dependent on donors (Bies, 2010), and accountability and transparency both with respect to the projects and activities is important, as well as the transparency of the organization itself (Cabedo, Fuertes-Fuertes, Maset-LLaudes, \& TiradoBeltran, 2016). A systematic evaluation system allows for this accountability and transparency and sets the stage for the sustainability of the NGO. It is important to maintain quality of service 
of the franchisee as it has a direct impact on the reputation of the franchisor (Kidwell, Nygaard, \& Silkoset, 2007) as well as on the social impact that the social franchise is attempting to make. Short term goals (e.g., increased access to education, healthcare, increased safety) as well as long term goals (increased ability to support oneself as an adult) should be assessed.

\begin{tabular}{|c|c|c|}
\hline & Asemota \& Chahine, 2017 & Foster Care Home Application \\
\hline Stage One & Pre-replication & $\begin{array}{l}\text { Determine reasons why franchising is needed, for } \\
\text { example by working with individuals living in the } \\
\text { locale to determine the need for services and how } \\
\text { they can best be provided, with a focus on } \\
\text { determining the population the foster home wishes to } \\
\text { serve. }\end{array}$ \\
\hline Stage Two & Replication readiness & $\begin{array}{l}\text { Create a team to conduct interviews and } \\
\text { assessments and provide recommendations for } \\
\text { social franchising (The Annie E. Casey Foundation, } \\
\text { 2013). The team can modify The Kinship Treatment } \\
\text { Foster Care Initiative Toolkit (Foster Family-based } \\
\text { Treatment Association, 2015) to assist in their } \\
\text { assessment. }\end{array}$ \\
\hline Stage Three & Replication capital & $\begin{array}{l}\text { Finding and making connections with donors who } \\
\text { are willing to support the mission of the organization } \\
\text { and provide the needed funding for the organization } \\
\text { on an ongoing basis. }\end{array}$ \\
\hline Stage Four & SOP manual development & $\begin{array}{l}\text { Create clear care guidelines for foster homes as well } \\
\text { as communication guidelines with the foster homes } \\
\text { and the head office to communicate information and } \\
\text { concerns. The guidelines should have information } \\
\text { about all forms of support that will be provided to } \\
\text { foster homes by the head office, including training for } \\
\text { staff). Make sure you consider the resources } \\
\text { available in the region where the foster homes are } \\
\text { being placed to determine the best methods of } \\
\text { communication and providing services. In } \\
\text { circumstances where the manual could be } \\
\text { considered a legal document, it should be written or } \\
\text { at the very least reviewed by a person with law } \\
\text { experience (Temple et al. 2011). }\end{array}$ \\
\hline Stage Five & Franchisee selection & $\begin{array}{l}\text { When selecting people to open additional foster } \\
\text { homes, the head office must consider if the } \\
\text { applicants have some of the financial and operating } \\
\text { resources to be able to open and support the foster } \\
\text { home. Potential applicants should also be assessed } \\
\text { to see if they are passionate about the goals and } \\
\text { values of providing foster care (Tracey and Jarvis } \\
2007 \text { ). }\end{array}$ \\
\hline Stage Six & Training, communication, support & $\begin{array}{l}\text { Foster homes should receive regular } \\
\text { communications from the head office to discuss } \\
\text { updates to procedures, funding updates, and to } \\
\text { discuss questions or concerns. The head office } \\
\text { should also determine the most effective ways of } \\
\text { communicating with foster homes based on the } \\
\text { technology available and provide any support if there } \\
\text { are any technological issues (Litalien 2006). The } \\
\text { head office should also provide training on a regular } \\
\text { basis to the managers and staff of the foster homes } \\
\text { (Soni \& Trivedi, 2016). }\end{array}$ \\
\hline Stage Seven & Evaluate social impact & $\begin{array}{l}\text { Foster homes should be evaluated on the safety of } \\
\text { the children, the safety of the home, medical and } \\
\text { educational support provided by the homes, as well } \\
\text { as the social and psychological supports provided by } \\
\text { the homes. Short term goals (e.g., increased access } \\
\text { to education, healthcare, increased safety) as well as } \\
\text { long term goals (increased ability to support oneself } \\
\text { as an adult) should be assessed. }\end{array}$ \\
\hline
\end{tabular}




\section{Possible Outcomes}

The social franchising approach offers a possibility of both larger impact as well as greater sustainability of the organization through careful consideration of standardizing processes, training, and partnerships with other organizations. Nevertheless, there are also several challenges that this model brings.

3.1 Opportunities and benefits. The social franchise model provides some economy of scale, where franchisees provide social services, and the head office provides administrative support, including developing standard procedures and training for franchisees. Adopting this model for Foster Home NGOs can create better sustainability and impact. Social franchising helps create a platform for knowledge exchange within a system. In order to be successful in social franchising, franchisors must encourage the exchange of knowledge and experiences between the different franchisees as that aids in developing a more successful social business model. This kind of knowledge sharing leads to more cooperation, which is essential for developing a strong organizational culture and long-term sustainability of the system. It may be most critical in contexts such as the Global South as a means of providing training, knowledge exchange, and developing standards of care when working with children.

One potential benefit to franchisors is the opportunity to rapidly expand their organization and their social impact with a lower financial burden than would be the case if franchisors operated numerous facilities themselves. Social capital provided by the franchisees reduces the risks to the franchisors that are often associated with business expansion while simultaneously allowing the franchisors to take advantage of the local knowledge and credibility of their franchisees (Asemota \& Chahine, 2017). This is a particularly important factor for NGOs that rely on donations to carry out their mission.

Franchisees also receive benefits from social franchising. Franchisees can rapidly expand their social impact as they receive financial support from the franchisor. In the case of foster homes, the social franchise model allows for outreach programmes and new care facilities to be developed more quickly given that many of the operating procedures and standards have been determined ahead of time. This can be a great advantage when the social issues that the NGO is seeking to remedy increases very quickly.

In the Global South, the urban population is quickly expanding as people move from rural communities looking for economic opportunities. Many approaches to this urbanization have adopted models from the Global North and, as a result, policy making related to poverty and urbanization has not always been as relevant as it could be (Parnell \& Robinson, 2018). NGOs are increasingly needed to provide social services and support for those whose economic mobility dreams did not work out (Zafeiropoulou \& Koufopoulos, 2013), as not only is urban poverty growing but it is likely that the extent of the poverty is underestimated (Lucci, Bhatkal, \& Khan, 2018). This situation of urban poverty is one where children are the first victims, and the number of vulnerable children increases rapidly. Therefore, it is an asset to be able to open foster homes rapidly, and the social franchise model can support this.

In social enterprises, the consistency of the standards set by the franchisor and the concomitant training that is provided offers the opportunity for multiplication of effort as it ensures that a standard is maintained by all franchisees. In case of foster care homes, this model can ensure that all homes are held to the same standards of care and operating procedures, giving a guarantee of quality care since each home must meet the standards and norms set by the organization. Further, these standards are supported by the franchisor in the form of communication of the standards and by providing training. The result of this careful development and training in expected operating standards also provides a tool for self-evaluation for franchisees as they have a benchmark for success. The training opportunities and consistency of support by the franchisor is a unique benefit of social franchising approaches (Sievering, Briegleb \& Montagu, 2105), and is of critical importance in taking care of vulnerable populations such as children.

Finally, the social franchising approach has the possibility to help in fundraising. As this approach is model based, the process can be replicated, and the results can be expected to be similar to the projects already implement by the franchisor. The success of ongoing franchisees can be used to show the success of the model undertaken by the franchisor. Additionally, since each of the franchise locations has similar activities, expectations, goals and operating standards, reporting of results, monitoring and evaluation can be standardized, reducing the resources required for evaluation and communication with external agencies and funders.

Applying the social franchise model to foster homes in the Global South provides the opportunity to assist a wide number of children and families as studies show that nonprofits that undertake a social franchise 
system grow twice as fast as other systems (Wei-Skillern \& Anderson, 2003). Using the social franchise model with foster care homes could open up foster care homes to a large segment of the population, providing more children with stability, nutrition, and education.

3.2 Challenges. Despite these opportunities, challenges also exist. One of the common challenges in franchising as a business model is the risk of negative reputation. When different entities operate under the same brand name, there is a possibility of one unit's negative image impacting the whole organization. Similarly, in the social franchising model, it becomes even more important to ensure that consistent standards are followed not only as the organization is directly delivering services to people in need, but also as they are dependent on external funds, which is highly impacted by reputation. Therefore, carefully selecting the franchisees' by evaluating the leadership and long-term commitment to the social goal can be critical.

Another challenge posed by the social franchising model is that it may seem deceptively simple and easy to implement. An evaluation of needs, and a careful assessment of the impact on communities, as well as individuals served is paramount. It is important that good intentions result in actions that have positive results rather than negative impacts. For foster care homes, this means that while taking care of children and providing them better opportunities is a noble endeavour, whole families and communities are also affected, therefore ensuring that providing services while maintaining a holistic view of the impact on children, families, and communities is important.

While the opportunities and benefits of the social franchise model are many, two important factors must be kept in mind. The first is that initiating this model is costly with respect to human resources and time. It takes time to create a franchise model and to develop it. The tools and training to ensure that standards are clear, consistent, and well communicated take time to develop. Once developed, the network of franchisees must be nourished, and evaluation and learning from projects must be consistently maintained. This approach requires a long-term view as it is a long-term relationship. Second, the results in a social franchise model are not as clearly observable nor measurable as those of a commercial franchise model. It is not easy to evaluate well-being, satisfaction, or happiness. With respect to social franchising foster care homes this can be particularly difficult given that the beneficiaries of the efforts are predominantly children in care, and therefore the desired results are both short term (safety, good nutrition and medical care) but also long term (life satisfaction, self-sufficiency). Thus, the longevity of the social franchise model is key to understanding its impacts and highlights again the challenge and importance of the long-term relationships between the franchisor and the franchisees.

Another challenge in undertaking a social franchising model is maintaining the balance between general requirements and particularistic considerations, especially as concerns the core mission of the social franchise. While some flexibility to meet contextual concerns is important, when franchisees adapt to specific local characteristics, it can lead to altering the original mission created by the franchisor (Ziolkowska, 2017). It is important to find the right balance between flexibility and standardization, as more standardization might compromise the level of impact in specific populations whereas more flexibility can lead to shifting the organizational mission in specific locations which can then reduce the impact of the social franchise.

Many areas in the Global South have diverse cultures in the populations served. For example, one challenge in implementing the social franchise model for foster care homes in India is a wide variety of religions and languages which may be practiced by children residing in the foster homes. India is home to a number of major religions, while the Constitution of India recognizes 23 official languages. When in an area with such a wide variety of languages and religions, it is extremely important for franchisors and franchisees to maintain an environment of cultural and religious sensitivity. Thus, it is important for social franchises to maintain some flexibility in their approach when working in culturally diverse local markets (Altinay, Brookes, Madanoglu, \& Aktas, 2014). The importance of maintaining flexibility is also key for foster care home franchises, as some of the criteria for operating procedures are out of control of the franchisor and are often evolving. For example, in many countries in the Global South, foster care home programmes must follow the criteria that are set by the government such as the number of children in a foster care home and the number of staff in a home. Operating procedures must be in line with such government regulations, and when criteria change, the changes must be implemented, communicated, and codified in standard operating procedures for franchisees. 


\section{Conslusion}

The social franchise model has a great deal to offer NGOs seeking sustainability of their organization in order to provide foster care for children in need. The model's emphasis on long-term commitment, standards, communication, training, and clear role responsibilities of franchisor and franchisee allow for streamlined use of resources. While initiating the model may require extra resources to develop standard operating, once in place, the model provides a method to capitalize on economy of scale, allowing more service to children in need.

However, the importance of maintaining the balance between standardization and flexibility must not be ignored, especially when serving children, families, and communities with diverse religions, languages, and cultures. The social franchise model relies on centralization for development and training of the franchisees, and that infers a certain amount of exclusivity to the franchisor. Being open and flexible to meeting the needs of specific populations is critical for the mission of the NGO to succeed.

\section{REFERENCES}

[1] Altinay, L., Brookes, M., Madanoglu, M., \& Aktas, G. (2014). Franchisees' trust in and satisfaction with franchise partnerships. Journal of Business Research, 67(5), 722-728. DOI:10.1016/j.jbusres.2013.11.034

[2] Alur, S. (2013). Social franchising. In Wankel, Charles (Ed) \& Pate, Larry E. (Ed). Social entrepreneurship as a catalyst for social change, (pp. 411-423). Charlotte, NC, US: IAP Information Age Publishing.

[3] Alur, S., \& Schoormans, J. P. (2011). Sustainable rural healthcare and social franchisee selection - an India study. Journal of Medical Marketing, 11(3), 230-236.

[4] Amies, M. (2000). Not-For-Profit Franchising? Franchising World, 32(6), 38-39.

[5] Asemota, J., \& Chahine, T. (2017). Social franchising as an option for scale. VOLUNTAS: International Journal of Voluntary and Nonprofit Organizations, 28(6), 2734-2762. DOI:10.1007/s11266-016-9763-7

[6] Beckmann, M., \& Zeyen, A. (2014). Franchising as a strategy for combining small and large group advantages (logics) in social entrepreneurship: A Hayekian perspective. Nonprofit and Voluntary Sector Quarterly; San Francisco, 43(3), 502.

[7] Berelowitz, D., Richardson, M., Towner, M. (2013). Realizing the Potential of Social Replication. London, UK: The Big Lottery Fund and the International Centre for Social Franchising.

[8] Bies, A. L. (2010). Evolution of nonprofit self-regulation in Europe. Nonprofit and Voluntary Sector Quarterly, 39(6), 1057-1086

[9] Bloom, P. N., \& Chatterji, A. K. (2009). Scaling social entrepreneurial impact. California Management Review, 51(3), 114-133. DOI:10.2307/41166496

[10] Brown, J. R., \& Dev, C. S. (1997). The franchisor-franchisee relationship: A key to franchise performance. The Cornell Hotel and Restaurant Administration Quarterly, 38(6), 30-38.

[11] Brown, M. D. (2014). The praxis of social enterprise and human security: An applied research agenda. Journal of Human Security, 10(1), 4-11.

[12] Cabedo, J. D., Fuertes, F. I., Maset, LI. A., \& Tirado, B. J. M. (2018). Improving and measuring transparency in NGOs: A disclosure index for activities and projects. Nonprofit Management \& Leadership, 28(3), 329-348.

[13] Cantwell, N.,Davidson, J., Elsley, S., Milligan, I., \& Quinn, N. (2013). Moving Forward : Implementing The United Nations Guidelines For The Alternative Care Of Children. Centre for excellence for looked after children in Scotland, UK.

[14] Conway, C. (2015). Scaling social enterprise through franchising. The International Journal of Entrepreneurship and Innovation, 16(4), 309-310. DOI:10.5367/ijei.2015.0201

[15] Crawford-Spencer, E. \& Cantatore, F. (2016) Journal of Marketing Channels, 23 (1-2), 47-59.

[16] Cumberland, D. M., \& Litalien, B. C. (2018). Social franchising: A systematic review. Journal of Marketing Channels, 25(3), 137-156. DOI:10.1080/1046669X.2019.1657757

[17] Eiðsdóttir, A. M. (2016). "Food, shelter, education, what else do they need?" Child sponsorship programs in India (Master's Thesis).

[18] Frame, J. (2017). Exploring the approaches to care of faith-based and secular NGOs in Cambodia that serve victims of trafficking, exploitation, and those involved in sex work. International Journal of Sociology \& Social Policy, 37(5/6), 311-326.

[19] Foster Family-based Treatment Association (2015). The Kinship Treatment Foster Care Initiative Toolkit. Retrieved from https://www.ffta.org/page/KinshipToolkit

[20] Hayllar, M. R., \& Wettenhall, R. (2011). Social Enterprise: What is it, and how can it be strengthened? Asia Pacific Journal of Public Administration, 33(1), 17-36.

[21] Hurley, K. (2016). From social enterprise to social franchise: An introductory guide to achieving scale through replication. (pp. 6- 55). Employment and Social Development Canada. 
[22] Kaufmann, P. J., \& Eroglu, S. (1999). Standardization and adaptation in business format franchising. Journal of Business Venturing, 14(1), 69-85. https://doi.org/10.1016/S08839026(97)00097-9

[23] Kellner, A. (2017). Human resource management standardisation and adaptation in franchises. Service Industries Journal, 37(9/10), 545-566. doi:10.1080/02642069.2017.1339794

[24] Khurshid, F., Butt, Z. U., \& Muzaffar, B. (2012). Occupational stress and turnover intentions among the Non-Governmental Organizations' employees. Language in India, 12(1), 100- 115.

[25] Kidwell, R. E., Nygaard, A., \& Silkoset, R. (2007). Antecedents and effects of free riding in the franchisorfranchisee relationship. Journal of Business Venturing, 22(4), 522-544.

[26] Litalien, B. C. (2006). Era of the social franchise: Where franchising and nonprofits come together. Franchising World, 38(6), 77-88.

[27] Lucci, P., Bhatkal, T., \& Khan, A. (2018). Are we underestimating urban poverty? World Development, 103, 297-310.

[28] Lyon, F., \& Fernandez, H. (2012). Strategies for scaling up social enterprise: Lessons from early years providers. Social Enterprise Journal, 8(1), 63-77.

[29] Mitlin, D. (2016). Cities for citizens in the Global South: approaches of non-governmental organizations working in urban development. In The Ashgate Research Companion to Non-State Actors (pp. 431-444). Routledge.

[30] Montagu, D. (2002). Franchising of health services in low-income countries. Health Policy and Planning, 17(2), 121-130. DOI:10.1093/heapol/17.2.121

[31] Parnell, S., \& Robinson, J., (2012) (Re)theorizing Cities from the Global South:Looking Beyond Neoliberalism, Urban Geography, 33:4, 593-617, DOI:10.2747/0272-3638.33.4.593

[32] Pereira, S. K., Kumar, P., Dutt, V., Haldar, K., Penn-Kekana, L., Santos, A., \& Powell-Jackson, T. (2015) Protocol for the evaluation of a social franchising model to improve maternal health in Uttar Pradesh, India. Implementation Science, 10(1), 77. DOI:10.1186/s13012-015-0269-2

[33] Sieverding, M., Briegleb, C., \& Montagu, D. (2015). User experiences with clinical social franchising: qualitative insights from providers and clients in Ghana and Kenya. BMC Health Services Research, 15(1), 1-11.

[34] Sivakumar, A. 1. S. A. n., \& Schoormans, J. L. (2011). Franchisee selection for social franchising success. Journal of Nonprofit \& Public Sector Marketing, 23(3), 213-225.

[35] Soni, B. K., \& Trivedi, J. (2016). Franchising in India: A study of the relationship between the franchisor and the franchisee. ASBM Journal of Management; Bhubaneswar, 9(1), 57-69. Retrieved from https://search-proquestcom.ledproxy2.uwindsor.ca/business/docview/1768170451/abstract/5247A34272234FBEPQ/58

[36] Stewart, D., \& Okubo, T. A world free from child poverty:A guide to the tasks to achieve thevision. UNICEF. [Retrieved from https://www.unicef.org/reports/world-free-child-poverty]

[37] The Annie E. Casey Foundation (2013). Kinship Process Mapping: A Guide to Improving Practice in Kinship Care. Retrieved from https://www.aecf.org/resources/kinship-process-mapping-full/

[38] Temple, N., Carey, C., Brereton, H. \& Jonsdottir, O. (2011). The social franchising manual. London, UK: Social Enterprise UK. Retrieved from: http://www.socialenterprise.org.uk/uploads/files/2011/11/social_franchising_manual.pdf.

[39] Tracey, P., \& Jarvis, O. (2007). Toward a theory of social venture franchising. Entrepreneurship Theory and Practice, 31(5), 667-685. DOI:10.1111/j.1540

[40] Weber, C., Kroger, A., \& Demirtas, C. (2015). Scaling social impact in Europe. Bertelsmann Stiftung (Ed.). Retrieved from: https://www.bertelsmann stiftung.de/en/publications/publication/did/scalingsocialimpact-in-europe/.

[41] Wei-Skillern, J. and Anderson, B. (2003). Non-profit geographic expansion: Branches, affiliates, or both? Social Enterprise Series no. 27, Harvard Business School Working Paper Series No. 4-011.

[42] Zafeiropoulou, F. A. \& Koufopoulos, D. N. (2013) The influence of relational embeddedness on the formation and performance of social franchising. Journal of Marketing Channels, 20(1-2), 73-98, DOI: $10.1080 / 1046669 X .2013 .747861$

Received: 2020-03-25

Revisions requested: 2020-04-30

Revised: 2020-05-08

Accepted: 2020-05-17 


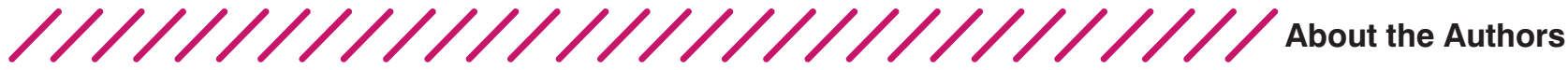

\author{
Catherine T. Kwantes \\ University of Windsor, Department of Psychology, Canada \\ catherine.kwantes@uwindsor.ca
}

Catherine T. Kwantes holds a PhD in Industrial Organizational Psychology and an MSc in Clinical Psychology. She is a full professor in the Psychology Department at the University of Windsor, Canada where she has worked for the past 18 years. During this time, she has been actively involved in projects related to Humanitarian Work Psychology. Her area of expertise is societal culture's influence on workplace attitudes and behaviours, including organizational culture and interpersonal trust in the workplace.

\section{Siddardh Thirumangai Alwar University of Windsor, Department of Psychology, Canada thiruma1@uwindsor.ca}

Siddardh Thirumangai Alwar is a Master's student in Applied Social Psychology at the University of Windsor. His research interest is in the area of Industrial Organizational Psychology, with a focus on psychological safety, organizational culture, burnout, and employee well-being.

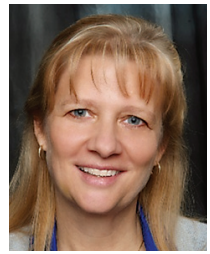

Stephanie J. Cragg University of Windsor, Department of Psychology, Canada cragg2@uwindsor.ca

Stephanie Cragg is currently a PhD student at the University of Windsor in Applied Social Psychology and is also a graduate of the Master of Social Work programme at the University of Windsor. Her area of interest is Community and Health Psychology, and her research focus is on the social and psychological effects of disability.

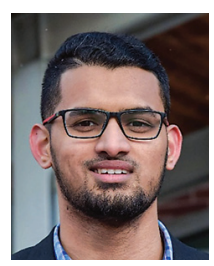

\section{Magali Feola, Project Coordinator Objectif France Inde, India magalifeola@gmail.com}

Magali Feola is a young humanitarian worker who specializes in childhood projects. She has been engaged in projects allowing a better access to education, notably in India. While in India, she supported a local NGO in the monitoring of foster homes. While the orphanages are often overcrowded in India, they worked for a better focus on

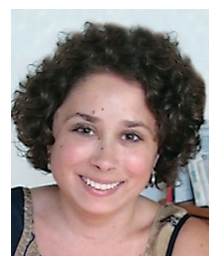
the individual and the personal development of each child. 